\title{
Special issue on global health
}

\author{
Geoff Royston
}

Received: 28 May 2012 / Accepted: 5 June 2012 / Published online: 14 June 2012

(C) Springer Science+Business Media, LLC 2012

\section{Introduction}

Improving global health is internationally recognised as one of the major human challenges for the 21 st century $[1,2]$. Resources available for this endeavour are limited, especially in low-income countries, and there is a concern not only to increase them but also to make better use of what there are. That requires a greater understanding of what resources will be required and where and how they should best be deployed, of what assists or impedes efficient and equitable delivery, and of what outcomes implementation is likely to achieve [3]. This presents a global health research challenge [4], not least for management science and operational research [5].

I am therefore delighted and privileged to introduce this special global health issue of the interdisciplinary journal Health Care Management Science which aims to help towards meeting this challenge by highlighting good case studies of analytical work on key global health issues and advances in developing useful methodologies for such work. Such papers have by no means been absent from the pages of Health Care Management Science in the past e.g. [6-8] but this is the first time a whole issue has been devoted to this subject.

Papers were invited from those involved in health management science, systems thinking or operational research work on a wide range of topics in global health including:

- global pandemics;

- diseases targeted in the UN millennium development goals: HIV/AIDS, tuberculosis and malaria;

\section{G. Royston $(\bowtie)$}

Burton Leonard,

Harrogate, UK HG3 3SJ

e-mail: geoff.royston@gmail.com
- health in emergency and disaster situations;

- supporting services and resources for global health e.g. pharmaceuticals, technology or workforce;

- methodological developments for analysis and research of global health issues.

The call for papers received a good response with some thirty submissions being received. From these, nine papers have been selected for publication in this special issue. Between them they exemplify all the topic areas of global health noted above, originate from work in countries with a wide range of income levels, and feature a variety of methodologies, as briefly reviewed below.

\section{Range of global health issues addressed}

Work on global pandemics features in the paper by Araz which considers possible policies for distribution of vaccine for pandemic influenza, based on a model of influenza transmission for an area in the United States. Another paper on vaccines, by Dhamodharan, using data from Bangladesh, looks at the challenge of reducing levels of vaccine wastage in outreach immunisation services, which can be as high as $85 \%$.

One of the diseases targeted in the UN millennium development goals-HIV/AIDS - features in two papers. Harries describes operational research for informing the scale up of antiretroviral therapy for HIV/AIDS in Malawi, looking at access to and impact of treatment. Santos compares the efficiency, across 52 low and middle-income countries, of services for the prevention of transmission of HIV from mother-to-child.

Another UN millennium development target- tuberculosis - also features in two papers. One, by Currie, analyzes 
TB epidemics in 221 countries to find clusters of countries with similar TB histories or TB distribution by age, and then seeks associations with factors such as HIV prevalence, immigration, or GDP per capita, as an aid to targeting resourcing for TB control. The other, by Langley, looks at a model-based approach to evaluation of innovative tools for diagnosis of $\mathrm{TB}$, and uses this to investigate alternative diagnostic strategies in Tanzania.

Disasters, whether natural or technological (or both, as in 2011 in Japan), are having ever greater global impact. The paper by Rauner looks at the challenge of coordinating staff, transport and other health care resources in mass casualty incidents, using an example from Austria, developing an operational policy model to help prepare emergency staff for improved planning and scheduling at emergency sites.

The health care workforce is a key underpinning resource for global health. The paper by Lagarde models the dynamics of career movements - especially between rural and urban areas - of nurses in South Africa, and investigates the likely impact of policies designed to influence these.

The complex health issues faced by developed and developing countries alike, and opportunities for low and high-income countries learning from each other about how to tackle these through taking a "whole systems" approach to decentralized health planning, are discussed in the paper by Thunhurst, drawing on examples from Pakistan, Malawi and Ireland.

\section{Variety of methodologies used}

The methodologies featured include soft systems and cognitive mapping (Thunhurst), field studies of comparison cohorts (Harries), cluster and principal component analysis (Currie), discrete event simulation (Rauner, Langley), Markov modelling (Lagarde), data envelopment analysis (Santos), mass action (differential equation) modelling (Araz) and optimisation methods using mathematical programming (Dhamodharan).

While the methods used in the papers published in the special issue do not cover all those important in global health-obvious omissions include system dynamics modelling, which played for example an important role in determining strategy for the global eradication of polio [9], and scenario analysis, which has been used by the United Nations Joint Programme on HIV/AIDS [10] — they do span a wide spectrum. The methods range from qualitative to quantitative and from descriptive, through predictive, to prescriptive analytics. This usefully illustrates how analysis and research to inform policy and practice in global health (as elsewhere) should not be wedded to any particular type of method or degree of quantification; key requirements, for whatever method is deployed, should be for rigour in approach and for appropriateness to the problem.

\section{4 "Real world" impact}

Management science is an applied science, so it will largely be judged, certainly by others, on its "real world" impact. This must surely be the case for global health and the call for papers for the special issue stated that priority would be given to papers on work demonstrating the highest actual or potential impact on policies or programmes addressing the greatest global disease burdens and health needs.

The published papers show how their authors have risen to this challenge. All of the papers indicate how the work they feature could be useful in informing policy and practice. Several are already being or about to be applied; the discrete-event simulation policy model in the paper by Rauner is currently being used by disaster-response services in Austria, the work by Harries has been used to influence national policy for treatment of HIV in Malawi, and policy advisers in Tanzania want to use the model described in the paper by Langley to evaluate alternative TB diagnostic strategies in the future.

\section{Enablers for future development}

The special issue does demonstrate several areas (some of which have been noted by others e.g. [11]) which need attention to enable further development of operational research and management science in global health. In particular:

- Improving Data Availability. Many of the papers in the special issue describe difficulties faced in obtaining data especially from lower income countries. Clearly this will be a continuing obstacle for some time, although there are signs of improvement; in particular the explosive growth of the internet and of mobile telephony in all parts of the world, not least in lower income countries. As well as directly improving access to information about health and healthcare for everybody, this will also improve the availability of data for research and analysis (see e.g. [12]).

- Deepening Research Capacity. Although the special issue includes a range of analytical work in low and middle income countries, the papers came from institutions located in the developed world. Such institutions will surely have a valuable continuing role to play in global health, but the limited research base in lower income countries needs to be built up [13]. Recent moves to accelerate this in the clinical and population 
health research domain e.g. [14] appear as yet to have extended little into the area of health management science: research on issues such as implementation [15] suffers neglect.

- Increasing Funding Levels. Operational research and management science appear to be considerably underused in the global health field. For example the Global Fund to Fight AIDS, TB and Malaria provides for 5$10 \%$ of each grant to be allocated for "monitoring, evaluation and operations research" (this would amount to some $\$ 150-\$ 300 \mathrm{~m}$ annually) and has produced guidance on this [16]. However, recent estimates are that projects are budgeting only an average of 3\% for operational research and actual spending is thought to be considerably less [17].

\section{Conclusion}

The papers in the special issue provide an encouraging indicator of interest and activity in analytical work on global health issues, not least in low and middle income countries facing the greatest health challenges.

Further development will depend in part on improvement in areas such as those noted above, but will depend also on better communication-between those doing mostly field based pragmatic operational research and those involved in developing and deploying tools of management science that could add analytic value, between health policy makers and managers with problems and analysts and researchers with ways to help address them, and between lower and higher income countries who can both learn from each other about tackling global health research and analysis issues.

Fora such as the WHO Evidence-Informed Policy network (www.evipnet.org) or the Healthcare Information for All 2015 network (www.hifa2015.org) can play a vital role in facilitating such communication. Network analysis is recognised as important in understanding global health [18], particularly because of the power of networks to transmit disease internationally. But networks can also spread knowledge about health and health care around the world, not least through research and policy networks. This special issue of Health Care Management Science aims to provide a modest example of that global spread of knowledge to improve health for all.

Acknowledgements Thanks are due to all the authors who submitted papers, particularly, obviously, to those whose work appears in the special issue but also to those whose papers could not be included on this occasion.

Any learned journal depends crucially on the reviewers who freely give their time and expertise to consider papers submitted to it. Our reviewers for the special issue on global health comprised a small army of 53 people, namely:

Tarek Abdel-Hamid
Michelle Adler

Heidi Albert

Pedro Barros

Daniel Barth-Jones

Nathaniel Bastian

David Bensley

Jos Blank

Sally Brailsford

Deon Canyon

Stephen Chick

Arfa Chokri

Leonid Churilov

Joseph Coyne

Brian Dangerfield

Subhash Datta

Luc Delesie

Peter Dick

Donald Enarson

Daniele Fabbri

Steffen Flessa

Daniel Friesner

Richard Gibbs

Peter Grove

Paul Harper

Neset Hikmet

Kamal Hussain

Armann Ingolfsson

Mark Isken

Seung-Chul Kim

Alexander Kolker

Reda Lebcir

Eric Marcon

Les Mayhew

George Miller

Lutchmie Narine

Albert Okunade

Graham Rand

Marion Rauner

Jonathan Rosenhead

Manuel Rossetti

Fiona Samuels

Richard Segall

Mike Smet

Honora Smith

Adolph Stepan

Colin Thunhurst

Vikram Tiwari

Meng-Chuan Tsai

Ann van Ackere

Shao-Jen Weng

Leroy White

Reza Yaesoubi

We owe them a considerable debt of gratitude.

Lastly, but most certainly not leastly, I would like to thank the Editor-in-Chief, Yasar Ozcan, and Jacqueline Lalic at the journal editorial office, for all their support throughout the entire preparation of this special issue.

Geoff Royston

Guest Editor

\section{References}

1. WHO (2007) Ten statistical highlights in global public health. World Health Statistics 
2. United Nations (2010) The Millennium Development Goals Report 2010. New York

3. WHO (2004) World Report on Knowledge for Better Health. Geneva

4. Global Ministerial Forum on Research for Health, Barnako, Mali 2008 (2009) Strengthening Research for health, development and equity. Global Forum for Health Research

5. Royston G (2011) Meeting global health challenges through operational research and management science. Bull World Health Organ 89:683-688

6. Flessa S (1999) Decision support for malaria-control programmesa system dynamics model. Health Care Mgt Sci 2:181-191

7. Anderson J, Chaturvedi A, Cibulskis M (2007) Simulation tools for developing policies for complex systems: modeling the health and safety of refugee communities. Health Care Mgt Sci 10:331-339

8. Brandeau ML, Zaric GS (2009) Optimal investment in HIV prevention programs: more is not always better. Health Care Mgt Sci 12:27-37

9. Thompson KM, Duintjer Tebbens RJ (2008) Using system dynamics to develop policies that matter: global management of poliomyelitis and beyond. Syst Dyn Rev 24:433-49

10. Joint UN Programme on HIV/AIDS (2004) Aids in Africa: three scenarios to 2025 . Geneva

11. Zachariah R, Harries AD, Ishikawa N, Rieder HL, Bissell K, Laserson $\mathrm{K}$ et al (2009) Operational research in low-income countries: what, why and how? Lancet Infect Dis 9:711-717
12. Tatem AJ, Qiu Y, Smith DL, Sabot O, Ali AS, Moonen B (2009) The use of mobile phone data for the estimation of the travel patterns and imported Plasmodium falciparum rates among Zanzibar residents. Malar J 8:287

13. Adam T, Ahmad S, Bigdeli M et al (2011) Trends in health policy and systems research over the past decade: still too little capacity in low-income countries. PLoS One 6(11):e27263

14. Ezeh AC, Izugbara CO, Kabiru CW et al (2010) Building capacity for public and population health research in Africa: the consortium for advanced research training in Africa (CARTA) model. Global Health Action 3:5693

15. Whitworth J, Sewankambo NK, Snewin VA (2010) Improving implementation: building research capacity in maternal, neonatal and child health in Africa. PLoS Med 7(7):e1000299

16. The Global Fund (2008) Framework for operations and implementation research in health and disease control programs. Geneva

17. Korenromp E, Komatsu R, Katz I et al (2007) Operational Research on HIV/AIDS, tuberculosis and malaria control in Global Fund-supported programmes: Round 1-6 grants, Proceedings of the 5th European conference on Tropical Medicine and International Health

18. Luke DA, Harris JK (2007) Network analysis in public health: history, methods and applications. Ann Rev Public Health 28:6993 